\title{
UPAYA MENINGKATKAN KEMAMPUAN BERHITUNG SISWA SEKOLAH DASAR KELAS IV DENGAN METODE JARIMATIKA
}

\section{AN EFFORT TO INCREASE NUMERACY SKILL OF STUDENT \\ WITH JARIMATIKA METHOD AT ELEMENTARY SCHOOL OF CLASS FOUR}

\author{
Oleh: \\ Ulfasari Rafflesia, Idhia Sriliana, Pepi Novianti \\ Jurusan Matematika Fakultas MIPA Universitas Bengkulu \\ ulfasari@unib.ac.id
}

\begin{abstract}
Community service activity aims to introduce and teach counting method of finger (jarimatika) as an alternative method of counting to complete the multiplication operation on the fourth grade students at SD Negeri 79 Kota Bengkulu. Counting method can be used to improve student learning outcomes in completing multiplication operations. This method can provide visualization of counting process, cheer up the child, not burdening the memory of the brain, and the tool is always taken. In addition, this method will make learning activities more fun so that the students become eager in learning. Based on the results of the dedication activities undertaken, it can be concluded that this activity is able to provide knowledge and skills to students of Class IV SDN 79 Kota Bengkulu about jarimatika method. Almost all students are very enthusiastic and interested in following this guidance activity although this jarimatika method is relatively new to them. In addition, this activity can improve students learning motivation and improve students' numeracy skills especially in multiplication operations.
\end{abstract}

Keywords: Counting, Jarimatika, Mathematics

\section{PENDAHULUAN}

Matematika merupakan subjek yang sangat penting di dalam sistem pendidikan di seluruh negara di dunia. Berbicara tentang matematika tidak akan lepas dari berhitung yang biasa disebut dengan nama aritmetika. Berhitung banyak digunakan dalam kehidupan sehari-hari, misalnya menghitung banyaknya siswa, menghitung jumlah mata pelajaran, dll, sehingga bisa dikatakan bahwa berhitung merupakan hal penting dalam kehidupan praktis sehari-hari. Mengingat pentingnya berhitung, maka pelajaran berhitung diajarkan secara formal di Sekolah Dasar (SD).

Bagi seorang siswa, belajar berhitung memang tidak mudah, karena banyak siswa yang takut dan malas jika harus belajar berhitung. Selama ini, sistem pembelajaran berhitung cenderung mengikuti metode hafalan. Pembelajaran seperti ini tidak tepat karena daya ingat anak-anak terbatas dan akan membebani memori otak. Akibatnya, siswa malas belajar, motivasi belajar menurun dan kemampuan berhitung menjadi rendah. Sebagai 
upaya untuk mengatasi masalah tersebut, pembelajaran berhitung paling tidak bisa dibuat menyenangkan, yaitu dengan mencoba aneka eksperimen matematika. Salah satunya adalah eksperimen dengan jari-jari tangan atau sekarang dikenal dengan istilah jarimatika.

Metode Jarimatika ditemukan oleh Wulandari (2004). Metode ini dikembangkan pada tahun 2000 sampai 2003. Meski hanya menggunakan jari tangan, dengan jarimatika kita mampu melakukan operasi bilangan KaBaTaKu (Kali Bagi Tambah Kurang) sampai dengan ribuan atau lebih. Jadi, jarimatika merupakan metode yang dapat digunakan untuk melakukan operasi hitung matematis seperti perkalian, pembagian, penjumlahan, dan pengurangan.

Metode berhitung jarimatika dapat digunakan untuk meningkatkan hasil belajar siswa dalam menyelesaikan operasi perkalian. Kelebihan penggunaan metode jarimatika yang tepat dapat memberikan visualisasi proses berhitung, menggembirakan anak saat digunakan, tidak membebani memori otak, alatnya selalu dibawa dan tidak pernah disita karena menggunakan jari. Kemudahan penggunaan metode jarimatika akan berdampak pada kecepatan dan ketepatan dalam menyelesaikan operasi hitung perkalian. Selain itu, penggunaan metode jarimatika akan membuat kegiatan belajar lebih menyenangkan sehingga siswa menjadi bersemangat dalam belajar.

Oleh karena itu, perlu dilakukan kegiatan pembelajaran metode berhitung jarimatika untuk menyelesaikan operasi perkalian pada siswa kelas IV di SD Negeri 79 Kota Bengkulu. Dengan menggunakan jarimatika diharapkan dapat mempermudah siswa dalam melakukan perhitungan matematika terutama operasi perkalian.

\section{METODE PENGABDIAN}

Metode yang digunakan dalam kegiatan pengabdian ini adalah:

a. Lokasi pengabdian

Penelitian dilaksanakan di SD Negeri 79 Kota Bengkulu yang beralamat di Jalan Sungai Rupat Kelurahan Pagar Dewa Kota Bengkulu.

b. Waktu pelaksanaan

Kegiatan pengabdian pembelajaran dengan menggunakan metode jarimatika ini dilaksanakan selama bulan September 2016 dengan melakukan pembelajaran tindakan kelas pada siswa kelas IVC dan IVD.

c. Khalayak sasaran

Khalayak sasaran utama dalam kegiatan ini adalah siswa kelas IV khususnya siswa kelas IVC dan IVD SD Negeri 79 Kota Bengkulu yang beralamat di Jalan Sungai Rupat Kelurahan Pagar Dewa Kota Bengkulu.

d. Memberikan materi metode jarimatika

Pada tahap ini, materi berhitung jarimatika akan diberikan di kelas dengan menggunakan modul belajar. Proses pembelajaran dilakukan dalam beberapa kali pertemuan. 
e. Melakukan post-test

Post-test ini dilaksanakan untuk mengetahui sejauh mana materi yang telah diberikan dapat dikuasai oleh siswa.

\section{HASIL DAN PEMBAHASAN}

\section{Realisasi Kegiatan}

Kegiatan pengabdian ini telah dilaksanakan di SD Negeri 79 Kota Bengkulu. Peserta dari kegiatan ini adalah siswa kelas IV C dan Kelas IV D SD Negeri 79 Kota Bengkulu sebanyak 31 orang siswa kelas $\mathrm{C}$ dan 33 orang siswa kelas D. Berikut adalah nama siswa kelas IVC dan IVD SD Negeri 79 Kota Bengkulu yang mengikuti kegiatan pengabdian pada masyarakat:

Tabel 1. Nama siswa Kelas IVC SDN 79 Kota Bengkulu

\begin{tabular}{llll}
\hline No. & Nama Siswa & No. & Nama Siswa \\
\hline 1 & Aan Aspiandra & 17 & M. Ibnu Sabilillah Andrian \\
2 & Aditia Pratama Nauli & 18 & M. Rafli Sofian \\
3 & Agung Rahmatulla & 19 & M. Sakka Santosa \\
4 & Albet Dodo & 20 & Mutia Indah Lestari \\
5 & Aldian Syahputra & 21 & Nabillah Chantika \\
6 & Apri Saputra & 22 & Nadia Oktarindi \\
7 & Chelsea Dwi Karlena & 23 & Natalia Putri A.S \\
8 & Citra Oktaria & 24 & Nopal Hariyanto \\
9 & Dea Ayu Permatasari & 25 & Patricia .S.O Sihotang \\
10 & Diky Kurniawan & 26 & Rasya Aulia \\
11 & Dimas Al Farizi Pratama & 27 & Reyzi Abi Mayu \\
12 & Dita Putri & 28 & Rezita Herdian Lauzah \\
13 & Guntur Dwi Kurniawan & 29 & Risky Alpiano Putra.M \\
14 & Hanisa Valentin & 30 & Vella Rizqullah Salsabilah \\
15 & Kezia & 31 & Yohanes \\
16 & M. Fitra Rizki & & \\
\hline
\end{tabular}


Tabel 2. Nama siswa Kelas IVD SDN 79 Kota Bengkulu

\begin{tabular}{llll}
\hline No. & Nama Siswa & No. & Nama Siswa \\
\hline 1 & Afdal Caniago & 18 & Rindia Amelia \\
2 & Bayu Setiawan & 19 & Selvi Intan Pratiwi \\
3 & Billy Novriansyah & 20 & Selvi Elsa Syafitri \\
4 & Deskan Dwi Setiabudi & 21 & Wulan Putri Ningsih \\
5 & Chintya Mishera & 22 & Yazid Omar Elhabsi \\
6 & Dika Yolansyah & 23 & Zahlul Dimas Pratama \\
7 & Enggar Okti Sabrina & 24 & Revaldo Prima Dani \\
8 & Firdinan Majulian & 25 & Rahmad Aditya Samlan \\
9 & Lestari Simamora & 26 & Sandy Juliansya Tobing \\
10 & Luisa Anatasya & 27 & Yohenes \\
11 & Malik Hamidi Karim & 28 & Fiky Rahma Hardianti \\
12 & M. Ikbal Pulungan & 29 & Fika Rahma Hardianti \\
13 & M. Rizki Prajaya & 30 & Julius \\
14 & M. Alfis Murhidayat & 31 & Jetli \\
15 & Putri Rizki Saidah & 32 & Agustianda Saputra \\
16 & Raihan Pirdaus & 33 & Fiter \\
17 & Raja Raisa Islamey & & \\
\hline
\end{tabular}

Tahapan pelaksanaan kegiatan pengabdian masyarakat ini secara garis besar meliputi:

a. Observasi awal

Kegiatan dilakukan di Kelas IV SD pada 2 kelas yaitu kelas IVC dan kelas IVD. Pemilihan kelas IV karena siswa telah mempelajari operasi matematika seperti penjumlahan, pengurangan, dan perkalian. Pada tahap awal kegiatan siswa diajak untuk mengingat kembali operasi penjumlahan bilangan dan operasi perkalian bilangan 6 sampai 10 .

b. Melakukan pre-test

Pre-test ini dilaksanakan untuk melihat seberapa jauh kemampuan siswa dalam berhitung perkalian. Setelah pre-test dilaksanakan, tim pengabdian melihat bahwa ada beberapa siswa yang takut pada saat diminta melakukan perhitungan perkalian, bahkan ada siswa yang belum bisa atau tidak hafal perkalian. Hal ini mungkin disebabkan daya tarik siswa terhadap mata pelajaran matematika masih kurang sehingga siswa cepat lupa terhadap materi berhitung yang sudah diberikan oleh guru.

c. Memberikan materi metode jarimatika

Materi berhitung dengan menggunakan metode jarimatika dilakukan di kelas dengan menggunakan poster dan materi ajar/modul. Agar menarik perhatian siswa, tim terlebih dahulu mengajak siswa melakukan permainan dengan 10 jari sehingga siswa menjadi bersemangat untuk mengikuti materi. Pemberian materi dilakukan di kelas 
setiap hari sabtu selama bulan September dengan waktu yang telah disepakati oleh guru kelas dan kepala sekolah yaitu pada kelas ekstrakurikuler sehingga tidak mengganggu proses belajar mengajar di kelas tersebut. Berikut adalah beberapa foto yang menggambarkan proses belajar materi metode berhitung dengan jarimatika di kelas IVC dan IVD:
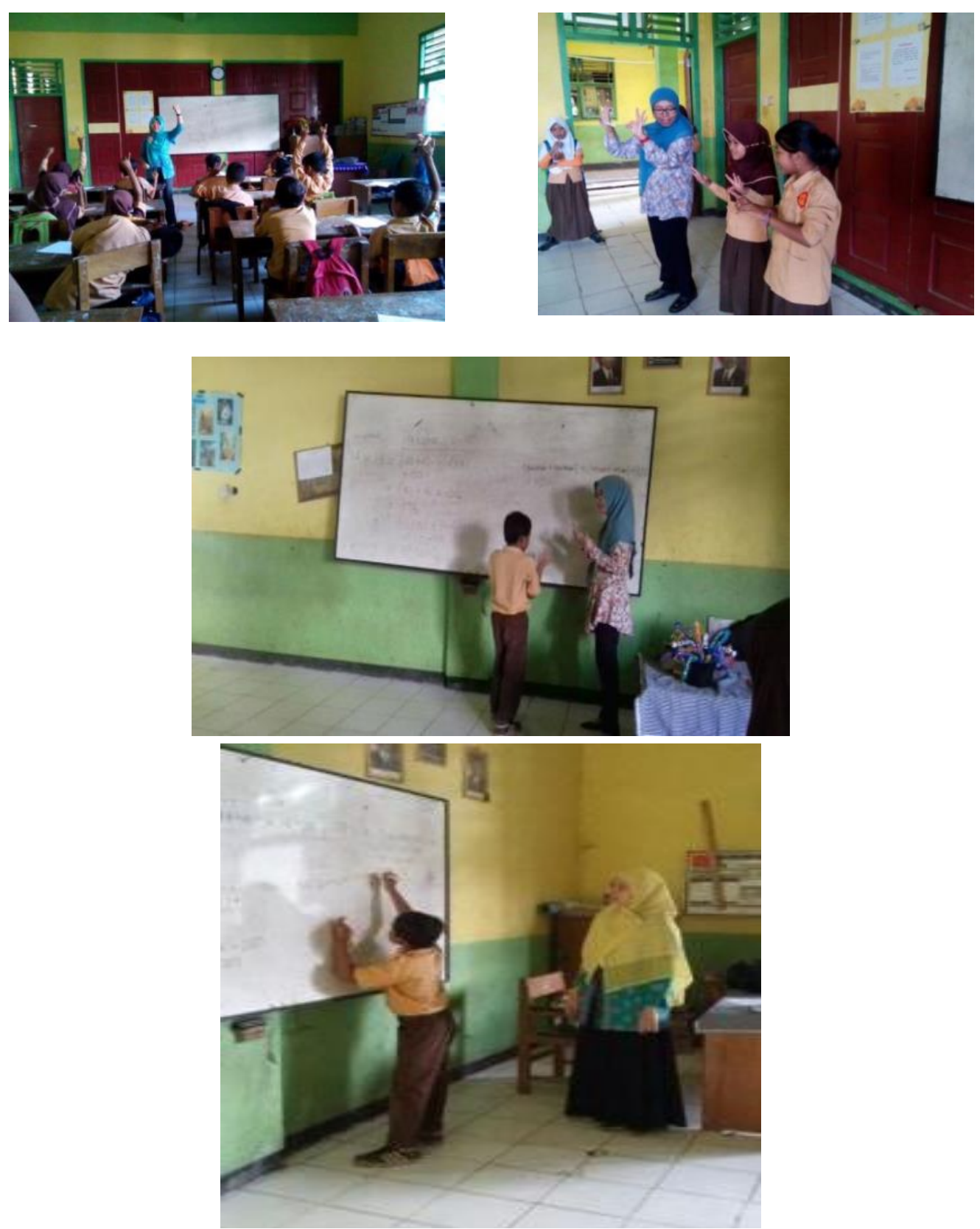

Gambar 1. Proses belajar metode jarimatika di kelas IVC dan IVD

Gambar 2. Siswa IVC dan IVD saat diminta melakukan perhitungan perkalian di depan 
d. Melakukan post-test

Setelah memberikan materi maka tim memberikan post test. Post-test diberikan agar bisa melihat sejauh mana serapan materi yang telah diberikan oleh tim dapat diterima oleh siswa. Setelah post-test diberikan, sekitar $80 \%$ siswa bisa menjawab dengan benar, dari 31 orang siswa kelas IVC, ada sekitar 6 orang yang masih perlu bimbingan agar bisa menjawab hasil perkalian, sementara yang lainnya bisa menjawab dengan benar. Sementara itu, untuk kelas IVD, dari 33 orang siswa, sekitar 8 orang masih perlu dibimbing saat menjawab soal perhitungan perkalian, atau bisa dikatakan $75 \%$ siswa bisa menyerap materi dengan baik.

e. Penutup

Pada akhir kegiatan, sebelum kegiatan ditutup, dilakukan pembagian hadiah pemenang kuis. Siswa yang dapat menjawab dengan cepat akan diberikan hadiah berupa bingkisan. Setelah hadiah diberikan, kemudian kegiatan ditutup dengan acara foto bersama.
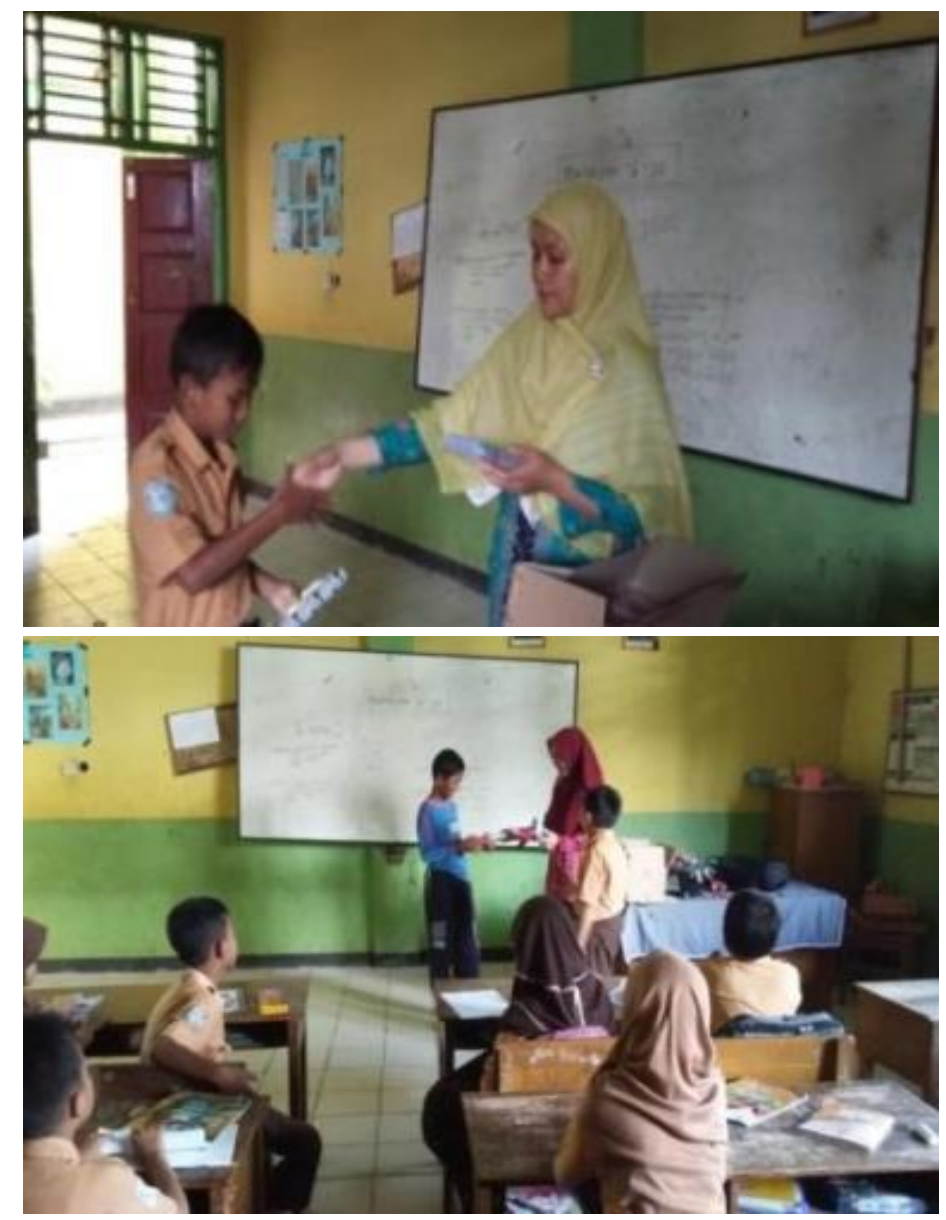

Gambar 3. Pembagian hadiah untuk siswa yang menjawab pertanyaan dengan benar 


\section{Evaluasi}

Berdasarkan hasil kegiatan yang telah dilakukan terlihat bahwa siswa cenderung kurang menyukai matematika. Dasar pemantauan ini adalah dari hasil tanya jawab yang dilakukan di awal kegiatan. Dari 31 orang siswa kelas IVC hanya 4 orang yang antusias untuk menjawab setiap pertanyaan yang diberikan. Namun, setelah mengikuti kegiatan pengabdian, siswa mampu menjawab pertanyaan perkalian dengan mudah. Setelah posttest diberikan, sekitar $80 \%$ siswa bisa menjawab dengan benar, dari 31 orang siswa kelas IVC, ada sekitar 6 orang yang masih perlu bimbingan agar bisa menjawab hasil perkalian, sementara yang lainnya bisa menjawab dengan benar. Sementara itu, untuk kelas IVD, dari 33 orang siswa, sekitar 8 orang masih perlu dibimbing saat menjawab soal perhitungan perkalian, atau bisa dikatakan $75 \%$ siswa bisa menyerap materi dengan baik.

Kegiatan ini juga menimbulkan kesan bahwa pelajaran matematika lebih mudah dimengerti jika dilakukan dengan metode belajar yang menyenangkan. Penggunaan waktu dan sumber daya yang disediakan dapat dikatakan sangat efektif melalui metode ini. Hal ini terlihat dari peningkatan rasa ketertarikan siswa dan semangat mereka dalam menyelesaikan soal, dimana siswa berlomba-lomba mencoba menyelesaikan dan menjawab soal sampai waktu habis.

\section{KESIMPULAN DAN SARAN}

\section{Kesimpulan}

Kesimpulan yang bisa diambil dari pelaksanaan pengabdian ini adalah:

1. Metode pembelajaran berhitung perkalian dengan menggunakan metode jarimatika dapat meningkatkan kemampuan berhitung siswa khususnya berhitung perkalian.

2. Metode pembelajaran ini juga bisa meningkatkan motivasi belajar siswa pada mata pelajaran matematika.

\section{Saran}

Kegiatan pengenalan metode berhitung jarimatika ini perlu dilanjutkan, sehingga siswa dapat terus mengoptimalkan kemampuan dan keterampilannya menggunakan jari dalam melakukan operasi matematika yang pada akhirnya dapat meningkatkan prestasi belajarnya khususnya untuk mata pelajaran matematika. Selain itu, diperlukan juga dukungan dan motivasi dari pihak sekolah dan orang tua siswa.

\section{DAFTAR PUSTAKA}

Astuti, T., 2013, Metode Berhitung Lebih Cepat Jarimetika, Lingkar Media, Jakarta. Aulia, M.F., 2009, Berhitung Dasyat dengan Jari Magic: Perkalian dan Pembagian, Buku 2. Pustaka Widya Tama, Yogyakarta.

Harmoni, 2001, Cara Cepat dan Mudah Berhitung dengan Abakus, Balai Pustaka, Jakarta. 
Purwandini, V., 2009, Jarimetika: Kaya Metode Perkalian dan Pembagian. Kawan Pustaka, Jakarta.

Simanihuruk, M., 2013, Pengembangan Perkalian Jari Magic, Yogyakarta, Penerbit Andi.

Wulandani, P.S., 2004, Jarimatika penambahan dan pengurangan (Teknik Berhitung Mudah dan Menyenangkan dengan Menggunakan Jari-jari Tangan), PT Kawasan Pustaka, Jakarta Selatan.

Wulandani, P.S., 2005, Jarimatika Perkalian dan Pembagian, PT Kawasan Pustaka, Jakarta Selatan. 